\title{
Biomarkers unbound
}

\author{
Controversies surrounding government walk-in rights or patent eligibility that grabbed headlines in recent weeks presage \\ broader changes in biomarker patenting.
}

$\mathrm{n}$ recent weeks, biotech patenting has been shaken by two high-profile legal decisions. In early March, the Indian government granted its firstever compulsory license to a Hyderabad-based generic company, Natco Pharma, which will manufacture and sell Bayer's patented anticancer drug Nexavar on the subcontinent. A couple of weeks later, in Mayo Collaborative Services v. Prometheus Laboratories Inc., the US Supreme Court struck down two patents on the use of biomarkers to help determine a patient's treatment. The Bayer decision is an important precedent in policies to tackle inappropriate licensing practices that suppress competition and restrict patient access to lifesaving products. But it is the Supreme Court decision and other changes in biomedical research that will have the most profound changes on patenting.

Intellectual property (IP) is central to incentivizing investment in innovation. It provides market exclusivity for products. It provides additional revenue to a company from out-licensing. And it can sometimes be used as a way of keeping products and/or technologies out of competitors' hands.

In Natco Pharma Ltd. v. Bayer Corp., the Indian government found that Bayer was keeping Nexavar not only out of competitors' hands but also out of Indian patients' hands. In India, Nexavar was found to be "exorbitantly priced" (Rs. 280,248 [\$5,382] per month as opposed to Rs. 8,800 [\$169] from Natco) and in short supply. Indeed, Bayer failed to find an Indian manufacturer to produce the drug and yet had imported only 200 bottles into the country in the three years after patent approval in 2008. The estimated demand for Nexavar is $\sim 23,000$ bottles per month.

If the Nexavar debacle tells us anything, it is that companies should think twice about inflexible licensing and product pricing, at least if they want to discourage other emerging nations from following India's example.

In Prometheus, the issue under consideration was not whether a patented product was accessible, but whether the subject matter covered by patents satisfied the legal requirements for eligibility. The IP involves methods for optimizing the safety and efficacy of a thiopurine drug when used to treat autoimmune gastrointestinal disease. The claims include the administration of a drug and the measurement of metabolites in the blood to be used in subsequent tailoring of dosage.

According to legal precedents, laws of nature, natural phenomena and abstract ideas are not eligible for patenting. And in Prometheus, the Supreme Court's unanimous decision was that the patents claim underlying laws of nature and "are consequently invalid." This prompted consternation among diagnostics companies (see p. 373) because the judges also failed to give any guidance as to what would have made the claims patentable. Companies count on court decisions to provide guidance on what is patentable subject matter and what is not. As a result some went so far as to claim that the decision might put all biomarker patents and even method-of-use drug claims in jeopardy. Whatever the case, it seems likely that biomarker patents will now be drafted with multiple claims that hedge bets as to where these 'patent eligibility margins' will be drawn. All more work/money for IP lawyers.

This leaves the larger question of where biomarker IP is heading. First, it is clear that biomarker research is already an area that academia, regulators and even industry regard as precompetitive. Several publicprivate biomarker research collaborations have now been established. This journal published the initial results of the Predictive Safety Testing Consortium (Nat. Biotechnol. 28, 431-494, 2010); other projects include the Foundation for NIH's Biomarkers Consortium and the Innovative Medicines Initiative's SAFE-T, PROTECT, SUMMIT, NEWMEDS, MARCAR and E-TOX.

Second, the role of patents in fencing off the DNA sequence landscape may be diminishing. Many of the junk DNA patents, which flooded patent offices during the genomics 'gold rush', are now expiring. And as more clinical centers adopt DNA sequencing and high-throughput 'omics tests, trillions of sequences, trillions of variants, and all manner of biological and behavioral marker data will enter the public domain. Patent thickets that would retard such research become more pernicious. And as such data sets become ubiquitous, the need to have open architectures to enable seamless data analysis and sharing will become a priority.

One can already see this starting to happen with the emergence of initiatives such as SAGE Bionetworks, the $\mathrm{i} 2 \mathrm{~b} 2$ informatics framework and Life Technologies' Genetic Care Interchange. In areas of rare disease, not-for-profit funding organizations, such as CHDI Foundation or the Parent Project Muscular Dystrophy, are also working with PLoS Currents (http://currents.plos.org/) to ensure that data from their projects are rapidly lodged in open repositories under a creative commons license. Other databases may be associated with open patent pools-exchanges that collect IP and license it on a nonexclusive basis. Thus far, these IP exchanges haven't exactly set the biotech world alight, but a few examples exist, such as the Golden Rice IP Pool, CambiaLabs' Agrobacterium/reporter technology, MPEG LA's Librassay for genetic tests and the UNITAID Medicines Patent Pool for HIV/AIDS.

Thus, the Prometheus decision looks like the beginning of the end for patents claiming isolated forms of 'naturally occurring' DNA sequences and their variants. This doesn't mean the end of biomarker patenting per se, merely that biomarker patent claims will migrate away from isolated sequences and their biological correlations to more complex diagnostic tests consisting of multiple biomarkers or algorithmic methods that enable new types of analysis.

If the coming age of digital medicine means the invalidation and demise of junk DNA patents, that is no bad thing. The good news is that the sheer scale and variety of biomedical data ushered in by evidence-based healthcare will create a myriad of exciting opportunities for biotech inventors and/or patents: new types of tests, new devices and diagnostics, and new analytical approaches. Thus, as one door closes, another opens. 